\title{
MINIMIZING SEDIMENT DEPOSITION IN URBAN DRAINAGE CHANNELS IN GHANA: CHANNEL SECTION DESIGN APPROACH
}

\author{
I.K. Nyameche \\ Department of Civil Engineering, Kwame Nkrumah University of \\ Science and Technology, Kumasi - Ghana
}

\begin{abstract}
The phenomenon of sediment deposition leading to the silting-up of drainage channels has been a major problem in the performance of urban drainage systems. Preventive and costly maintenance measures are often employed to mitigate the problem. In the area of design, critical or self-cleansing velocity methods have been used to achieve certain levels of flushing-out of sediment load in the channels. As an alternative to the current design practices in Ghana, this study presents the channel section approach. Deposition of suspended sediment in channels takes place mainly because of velocity fluctuations in the channel. In this study, therefore, a channel section capable of maintaining a constant vertical velocity distribution is presented. The advantage of the constant velocity channel section is that it minimizes the velocity fluctuations in the channel and subsequently reduces the deposition of sediment in the channel.
\end{abstract}

Keywords: Sediment, silting, urban drainage channels, constant velocity, Self cleansing. INTRODUCTION

Sediment generated from urban and peri-urban catchments often gets deposited in urban drains, and this constitutes a major factor to the poor performance of urban drainage systems in Ghana. The movement of sediment through a drainage catchment is a complex multi-stage process. The sediment-laden runoff flows first, as overland flow, and eventually into channels. The transport of sediment continues in the channels until at some points along the channels sediment deposition occurs as a result of insufficient kinetic energy of the flowing water to keep some of the sediment particles in suspension. This is very common in channels constructed in flat terrains. When the sediment deposition continues for a long time without desilting the channels, they get desilted and cause flooding of various degrees of magnitude as a result of the reduction of their carrying capacities.

A silted channel encourages prolific weed growth in it when soil moisture conditions are favourable. The vegetation increases the roughness factor in the channel, decreases the effective flow area of the channel, hence, reducing the ability of the channel to carry stormwater.

When the sediment is concentrated at sections (e.g. entrance to culverts), ponding of water often occurs upstream and creates convenient breeding grounds for some disease causing agents. Silted roadside drains produce ponding on roads because of their inability to contain the large quantities of water flowing into them. When this happens vehicular traffic is impeded. Some localized floods are caused by heavily silted channels whose carrying capacities have been drastically reduced.

In the case of buried or completely covered storm channels, the deposited sediment has the ability to act as a pollutant store or generator. These pollutants are only stored temporarily, and are usually released under flood flow conditions, and often cause foul conditions at the outfall points. Biochemical changes in the bed of sediment can result in septic conditions, releasing gases that can be highly corrosive to the channel material.

Knowing that silting will occur in channels after their construction, it is always recommended by drainage engineers to undertake regular maintenance activities such as desilting, dredging, etc, in the channels. Experience has however shown that this is easier said than done. Plate 1 shows large quantities of sediment and garbage removed from a roadside drain of a paved road in the Central Business District (CBD) of Tamale, the capital town of Northern Ghana, while Plate 2 shows desilting of one of the streams in Accra. 
Lack of regular maintenance during the previous years has caused the accumulation of the sediment and garbage in the drain. Extensive, regular sediment removal is a difficult and expensive process. In a press release on June 17, 2002 the Chief Executive of the Accra Metropolitan Assembly (AMA) underscored the expensive nature of desilting drains; he stated that the AMA spent three hundred thousand US-dollars $(\$ 300,000)$ in 2001 to desilt drains in the Accra metropolis, and that a larger amount would be needed to carry out a similar job in the year 2002 if flooding was to be minimized (Okine, 2002).

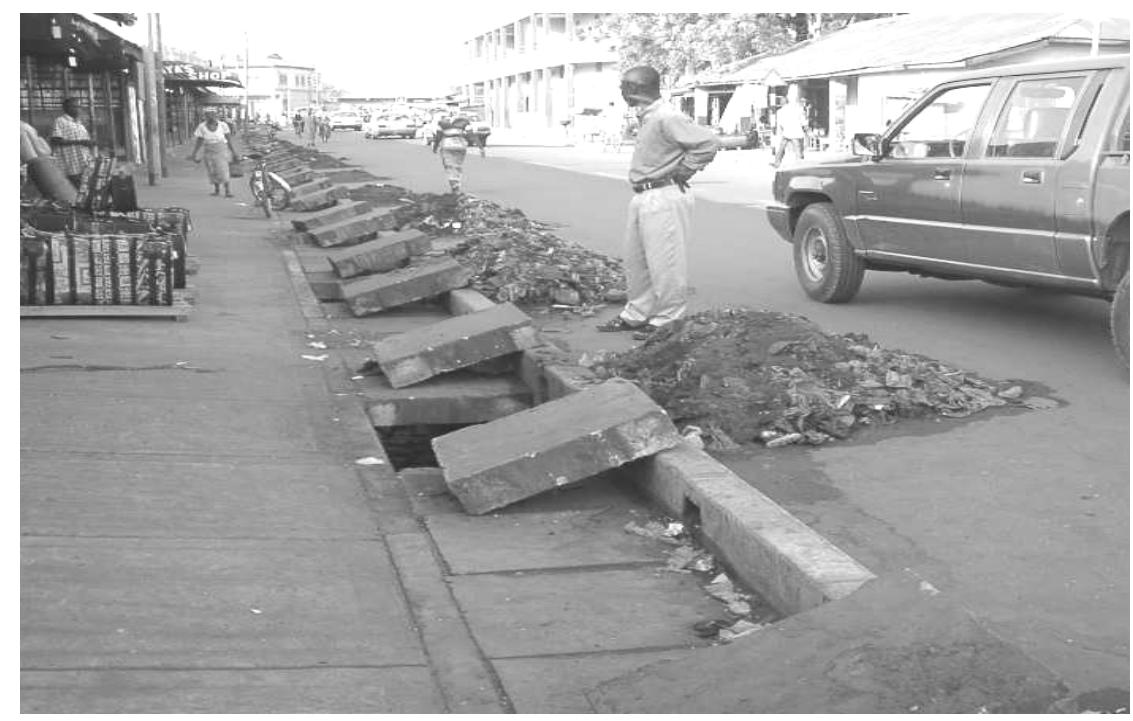

Plate 1: A silted covered roadside concrete U-drain in Tamale being desilted

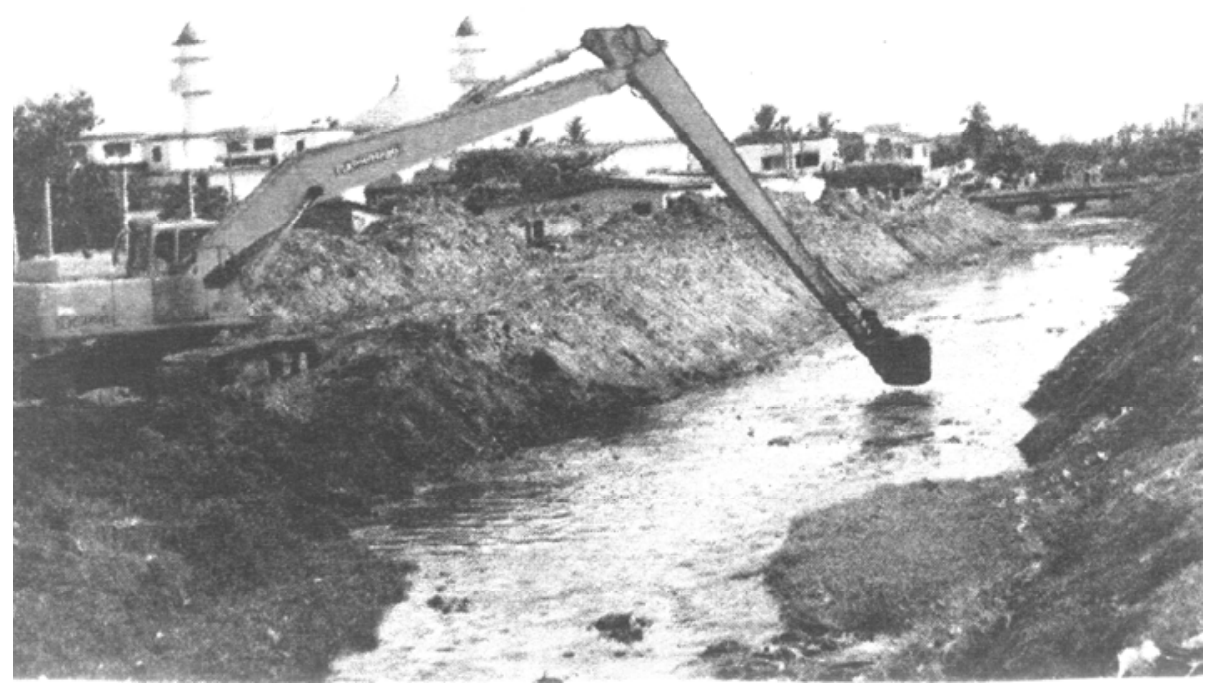

Plate 2: Desilting of a Stream Channel in Accra

Mitigation measures which are currently practiced in Ghana include solid waste management, covering of open drains, use of buried pipes as drainage channels, and paving/grassing/planting of trees on catchments. These measures are meant to minimize the production of sediment from the surrounding catchments and the 
entrance of sediment into urban drainage channels.

The traditional hydraulic analysis and design of a drainage channel will include the determination of its capacity to carry the design discharge and the choice of a minimum "self-cleansing velocity" for the channel. The dimensions and shape of the channel are, in most cases, determined using the "best hydraulic section" concept and/or approved design standards of the establishment/client/country. In an earlier paper Nyameche (1996), the author examined the weakness of the "best hydraulic section" concept in the design of prismatic channels used for urban drainage systems in Ghana. A conceptual channel section to improve upon the hydraulic performance of drainage channels, especially with respect to their ability to transport sediment, was then presented. The purpose of this paper is to develop the proposed channel section and to discuss how it can be used to design stormwater drainage channels in Ghana. A brief discussion is first presented on sediment and its behaviour with respect to velocity distribution in channels; this is meant to provide an introduction to the significance of the channel section to be developed in the study.

\section{Sediment Transport in Channels}

Water is a powerful agent for transporting material. Streams can move material in several ways. Heavier particles may be rolled or pushed along the channel bed; the material transported in this way is described as the bed load of the stream. The largest grain a stream can move as bed load is called its competence. The competence of a stream changes, not only from upstream to downstream sections along the channel, but also from time to time at the same spot because of changes in stream velocity with respect to location and time. Capacity refers to the maximum amount of sediment/debris of a given size that a stream can carry in traction as bed load. Experiments have shown that this parameter depends upon stream gradient, discharge, and the calibre of load. Some of the material is light or fine enough to be carried along in suspension, and supported by the flowing water; this type of load is called the suspended load. Suspended sediment normally clouds the water in the channel and gives it a muddy appearance. The distribution of suspended load varies with depth below the surface of the stream (Kennedy and Brooks, 1963). The highest concentration is near the bed and decreases rapidly from the bottom of the channel to the surface. There is also a distinct variation in suspended load for grains of different sizes. Observations have showed that there is a fairly good correlation between suspended load and stream discharge (Leopold and Maddock, 1955). Material of intermediate size may be carried in short hops along the channel bed by a process called saltation. Finally, some substances may be dissolved in the water; and this is known as the dissolved load. The total quantity of material that a stream transports by all these methods is its load.

From the above definitions and observations, it is clear that sediment discharge, whether as bed load, suspended load or dissolved load exhibits both temporal and spatial variations in a stream. The factors that determine the sediment/debris load are stream discharge, velocity, gradient, channel morphology, bed roughness, and the physical characteristics of the fluid and of the grains in the load. For prismatic channels used in urban drainage, factors such as stream gradient, channel morphology, bed roughness and the physical characteristics of the fluid can be assumed to have constant values for some channel sections during their design life spans. This enables the designer to estimate channel velocities which will be able to achieve efficient flushing of sediment/debris through the drains. Both suspended and bed loads are of interest in the design of drains.

\section{Velocity Distribution in Open Channels}

When drainage channels are designed to achieve a given self-cleansing velocity it is normally assumed that this velocity is: (i) able to create and maintain a tractive force required to entrain a given grain size of sediment; and (ii) sustained or exceeded at all sections along the channel length. 


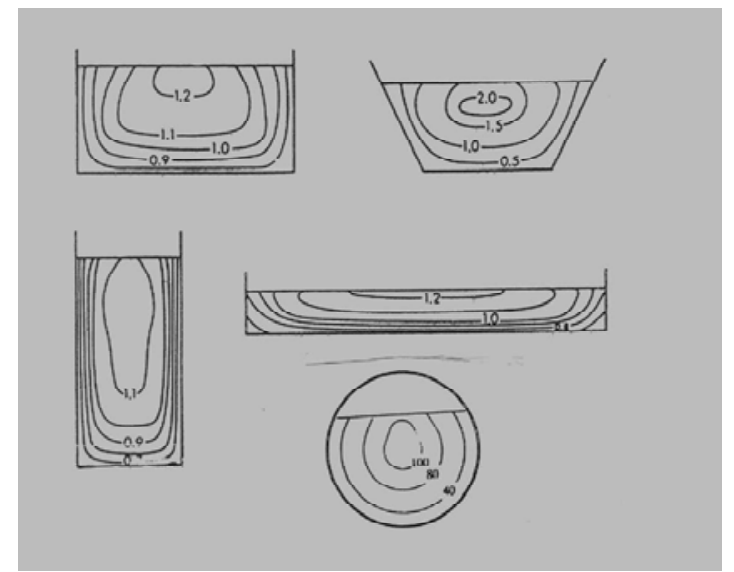

Figure 1:Velocity Distributions in Transverse Cross-sections in Prismatic Channels of Different Shapes. Lines are Isovels, i.e., Lines of Equal Velocity. [After Lane (1937)]

In practice, however, the velocity distribution in open channels varies both in the vertical and horizontal directions. Examples of velocity variation that occurs in some prismatic channels are as shown in Figure 1. The distribution of velocity, in the vertical direction, over the channel cross-section is expressed for both the lamina and turbulent flow conditions in an open channel by equations (1) and (2).

For lamina flow:

$$
V_{h}=\frac{g}{k} h\left(H-\frac{h}{2}\right) S_{o}
$$

And for turbulent flow:

$$
V_{z}=2.5 v_{f} \log _{e}\left(\frac{z}{z_{o}}\right)
$$

\footnotetext{
Where $\mathrm{h}$ and $\mathrm{z}$

$=$ depth of water above the channel bottom;

$\mathrm{H}=$ total depth of channel;

$\mathrm{V}_{\mathrm{h}}, \mathrm{V}_{\mathrm{z}}=$ velocity of flow at any point in the channel;

$\mathrm{Z}_{\mathrm{o}}=$ depth of water in channel where $\mathrm{V}=\mathrm{O}$;

$\mathrm{V}_{\mathrm{f}}=$ shear velocity;

$\mathrm{S}_{\mathrm{o}} \quad=$ Slope of channel bed;

$\mathrm{g} \quad=$ acceleration due to gravity;

$\mathrm{k}=$ kinematic viscosity of water.
}

Equation (1) is parabolic while equation (2) is logarithmic. Since drainage channels are designed for turbulent flow conditions, this study will only focus on equation (2)

The importance of velocity distribution in channels lies in the fact that a stream's ability to pick up and transport its sediment load depends upon the energy of the stream. 
At any point along a horizontal section in an open channel, the total energy is equal to the sum of the potential energy, $\mathrm{E} p$, and the kinetic energy, $\mathrm{E}_{\mathrm{K}}$. In equation form:

$$
E_{p}=W_{z} \ldots(3 a) ; \text { and } \quad E_{k}=\frac{M V^{2}}{2} \ldots(3 b)
$$

where $W_{Z}$ is weight of a particle of water, $\mathrm{z}$ is the head of water above a given datum, $M$ is the mass of the water particle, and $V$ is the velocity of the water at that point. Total energy across the channel section in the horizontal direction is influenced only by the velocity. The variation of energy of a water particle in the vertical direction along the channel section is a function of both the water head and the water velocity. Total energy, then, is mostly influenced by the velocity of flow.

Variations in a channel's velocity across its section and along its length are reflected in the sediments deposited at different points. The faster the velocity of flow, the larger and denser are the particles moved and carried along (see figure 2). The loss of hydraulic capacity due to deposited sediment on the channel bottom can vary considerably with the flow conditions as shown in Figure 3.

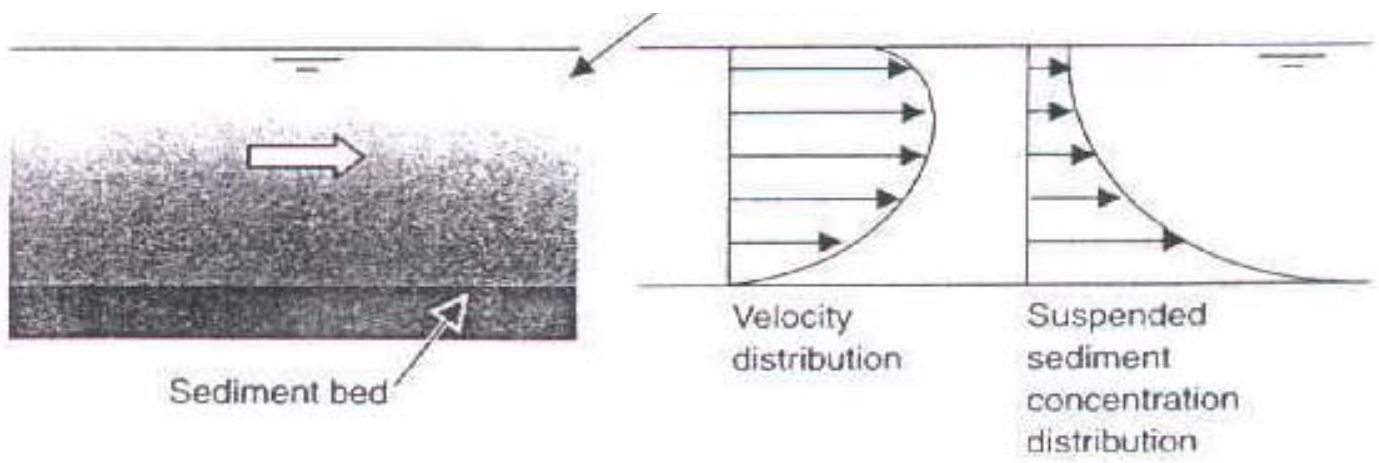

Figure 2. Velocity and suspended sediment distribution in dry weather [After Butler and Davies (2000)]

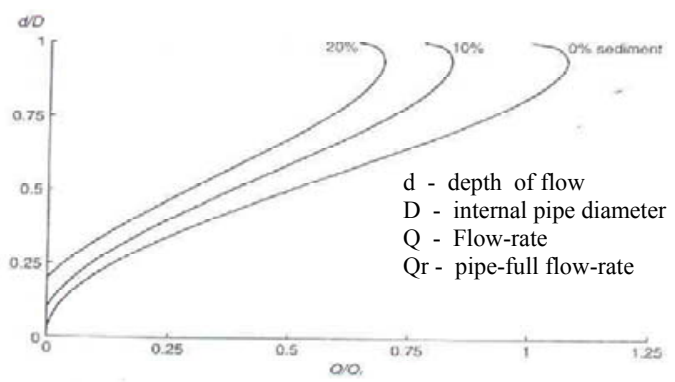

Effect of sediment bed on flow capacity of sewers

Figure 3. Effect of sediment bed on flow capacity of sewers [After Butler and Davies (2000)]

\section{Design of Stormwater Channels to Control Sediment Problems: A Brief Review}

Drainage engineers have long recognized the inevitable and ubiquitous presence of sediment in stormwater and the problems they cause in urban drainage systems. To cope with these problems various design measures have been included in the drainage systems to (i) exclude larger sediment particles from the channels, (ii) encourage sedimentation at some sections in the channel so as to reduce the sediment load in the downstream section, and (iii) achieve self-cleansing velocities within the channels. 
Exclusion of large sediment particles have been achieved by the use of gully pots in buried stormwater sewers, while metal grates have been used in open channels. Poor maintenance has been the cause of the many problems associated with these measures.

Catch basins and sediment detention ponds located at designed positions within the stormwater drainage system have been used to slow down flow velocities so as to encourage deposition of some of the suspended sediment in the storm water. Again, where these have not been given the necessary maintenance care, they have often been blamed for increasing pollution of stormwater during the initial runoff stages due to septic action in the trapped water and sediment between storms.

The state-of-the-art literature in stormwater sewer design shows that conventional methods (BS EN 7524:1998) and the Construction Industry Research and Information Association (CIRIA) method (Ackers et al., 1996; Butler et al., 1996a; 1996b) are the common methods used to achieve "self-cleansing" flow velocities in urban stormwater drainage systems.

With the conventional method a minimum self-cleansing flow velocity is specified and this should be achieved at a particular depth of flow or with a particular frequency of occurrence - at least once a in day during dry weather flow conditions. The minimum velocity specified by the British Standards (BS) and the European Standards (EN) - BS EN 752-4 for sewers up to a Nominal Diameter of 300mm (DN 300) is $0.70 \mathrm{~m} / \mathrm{sec}$. Although this method is widely used with much success in many cases a single value of minimum velocity, unrelated to the characteristics and concentration of the sediment or to other aspects of the hydraulic behaviour of the channel, does not properly represent the ability of the channel flows to transport sediment. In addition, flow rates and the sediment entering an urban stormwater drainage system can vary considerably with time and location. The implication is that a channel designed to be selfcleansing in normal conditions is still likely to experience sediment deposition during periods of low flow and/or high sediment load.

The velocity distribution, in the vertical direction, in an open channel - as shown in equation (2) explains one of the weaknesses of the "self-cleansing velocity" approach in the design of channels. The ability of the flowing water to flush out sediment/debris in a channel designed with the self-cleansing velocity approach will only be realized in the top 0.6 portion of the depth of the channel; this being so because of the fact that the self-cleansing velocity is almost always taken as the average velocity of flow in the channel. Any particles moving below the 0.6 depth section of the channel can easily be deposited, especially when the velocity of flow equals the minimum self-cleansing velocity specified for the flow in the channel. On the other hand if the velocity of flow is exceeded far above the designed value, this may cause scouring of the top sections of the channel sides.

The CIRIA method (Ackers et al., 1996; Butler et al., 1996a; 1996b) was developed in an attempt to relate minimum velocity to all the factors that affect it most, namely: pipe size and roughness, proportional flow depth, sediment size and specific gravity, degree of cohesion between the particles, sediment load or concentration and the presence of a deposited bed. This method defines self-cleansing as: "An efficient self-cleansing channel is one having a sediment - transporting capacity that is sufficient to maintain a balance between the amounts of deposition and erosion, with a time-averaged depth of sediment deposit that minimizes the combined costs of construction, operation and maintenance," (Ackers et al., 1996). The important aspect of this definition is that it does not necessarily require channels to be designed to operate completely free of sediment deposits if more economical overall solutions can be achieved by allowing some deposition to occur. Although the CIRIA method is a significant advance over conventional approaches, it should be noted that it does have limitations (Arthur et al., 1999). The main one is that it is based mainly on data from laboratory pipe-flume experiments using single-sized, granular sediment. This is clearly a simplification of the operating conditions of real urban stormwater drainage systems.

\section{The Constant Velocity Concept}

The conventional channels - rectangular, triangular, trapezoidal, circular, etc channels- have logarithmic velocity distribution in the vertical direction across the channel section. This makes the channels to suffer from large fluctuations in the velocity. The constant velocity channel is meant to overcome the defects of 
velocity fluctuation in the vertical direction within the channel so that designed self-cleansing velocities are experienced across the whole section of the channel. Flushing of sediment/debris will consequently be more efficient in constant velocity channels.

\section{The Constant Velocity Open Channel Section}

The variation of velocity, in the vertical direction, in a prismatic open channel, for a constant bed slope, depends on the hydraulic radius R. It follows that, for a constant velocity at all depths of flow in the channel, (i) the channel should be bottomless - to eliminate zero velocity at the channel bottom; (ii) the shape of the channel section should be such that the hydraulic radius $\mathrm{R}$ remains constant. This implies that, for increasing depth of flow in the channel, the ratio of the cross-sectional area of flow A and the corresponding wetted perimeter $\mathrm{P}$ should remain constant. This means that:

$$
\begin{aligned}
\frac{d A}{d P} & =\text { Constant } \\
\text { or } \quad \frac{d A}{d P} & =R
\end{aligned}
$$

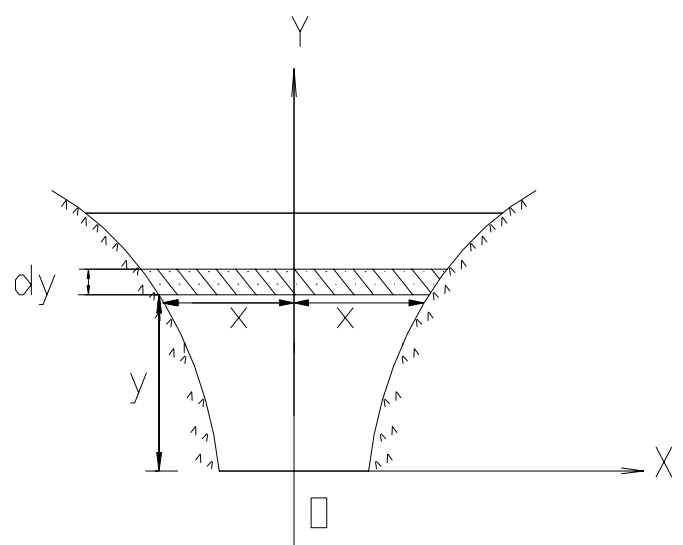

Fig. 4. Shows such a Channel Section.

Take the origin at 0 (the centre of the bottomless lowest section of the channel), and consider an elemental area dA of depth dy;

$$
\therefore d A=2 x d y
$$

Let the wetted Perimeter of the elemental section $=\mathrm{dP}$

$$
\begin{aligned}
& \quad \therefore d P=2 \sqrt{(d x)^{2}+(d y)^{2}} \\
& \text { i.e. } \quad R=\frac{d A}{d P} \\
& =\frac{2 x d y}{2 \sqrt{(d x)^{2}+(d y)^{2}}}
\end{aligned}
$$




$$
\begin{aligned}
& \text { or } \quad x^{2}(d y)^{2}=R^{2}\left[(d x)^{2}+(d y)^{2}\right] \\
& \text { or } \quad x^{2}\left(\frac{d y}{d x}\right)^{2}=R^{2}\left[1+\left(\frac{d y}{d x}\right)^{2}\right] \\
& \text { or } \quad\left(\frac{d y}{d x}\right)^{2}\left[x^{2}-R^{2}\right]=R^{2} \\
& \text { or } \quad d y=\frac{R d x}{\sqrt{x^{2}-R^{2}}}
\end{aligned}
$$

For $\mathrm{x}>\mathrm{R}>\mathrm{O}$, integrating equation (8) gives:

$$
\begin{aligned}
& y=R \ln \left[x+\sqrt{\left(x^{2}-R^{2}\right)}\right\rfloor+C_{1} \\
& \text { or } \quad y=R \cosh ^{-1}\left(\frac{x}{R}\right)+C_{2} \\
& \text {.. }
\end{aligned}
$$

Equations (9) and (10) both give the curves forming the sides of the constant velocity channel section; it is bottomless.

The constant of integration $\mathrm{C}_{2}$ in $\mathrm{Eq}(10)$ can be obtained if the value of $\mathrm{x}$ is known at $\mathrm{y}=0$. A less complex form of Eq. (10) is obtained if $\mathrm{x}$ is taken as $\mathrm{R}$ at $\mathrm{y}=0$. Hence from Eq. (10),

$$
\begin{aligned}
& 0=\mathrm{R} \operatorname{Cosh}^{-1}(1)=\mathrm{C}_{2} \\
& \text { i.e. } \mathrm{C}_{2}=0 \text {, and Eq. (10) becomes; } \\
& y=R \operatorname{Cosh}^{-1}\left(\frac{x}{R}\right)
\end{aligned}
$$

For practical application the section below the $\mathrm{y}=0$ axis can be of any appropriately designed regular prismatic channel, such as triangular, semi-circular, or trapezoidal section. This regular section would normally handle low and dry weather flows; the top width will be equal to $2 \mathrm{R}$, and the designed constant velocity in the constant-velocity channel is assured to exist at the top larger section which will handle larger flows. This channel section will be particularly suitable for urban areas with relatively flat slopes, and for outfall drainage channels carrying urban storm water through flat lagoon areas into the sea. Because of its relatively wide top section compared to other channel sections with the same cross-section areas, the constant velocity channel section is highly recommended for use as outfall drainage channel in areas where adequate lateral space is available.

The practice of modifying a hydraulic channel with a theoretical profile, to make it practicable is common in hydraulics. A typical example is the proportional- flow weir in which the discharge varies linearly with the head of water $\mathrm{H}$. The sides of the weir have a parabolic shape given by the equation: 


$$
x=\frac{k}{\sqrt{y}}
$$

where $x$ and $y$ are the width and depth, respectively, of the weir.

Where $\mathrm{k}$ is a constant and the centre of the crest is taken as the origin. In equation (12), $\mathrm{x}$ becomes infinite at $y=0$, thus making the weir impracticable.

Sutro modified the shape of the profile - to make it functional (Rouse, 1950).

The equation of the curved boundary after Sutro's modification is:

$$
\frac{x}{a}=\left(1-\frac{2}{\pi} \tan ^{-1} \sqrt{\frac{y}{a}}\right)
$$

where $a$ and $b$ are dimensions of the rectangular portion designed for the portion of the weir below the $\mathrm{y}=0$ axis

\section{Design Application}

When it is required to use the Constant Velocity Channel as an urban drainage channel, the following design procedure is recommended:

i) Estimate the peak discharge Q to be carried by the drain; this must include the dry weather flow.

ii) The bottom regular channel should be designed to accommodate the dry weather flow $\mathrm{Q}_{1}$ and the top width of the bottom channel should be taken as $2 R$ ( $R$ is as defined in equation (4)).

iii) The discharge to be carried by the constant velocity section of the channel is: $\quad Q_{2}=Q-Q_{1}$.

iv) Depending on the characteristics of the runoff, a self-cleansing velocity $\mathrm{V}$ is chosen as the constant velocity for the channel.

v) The area of flow for the constant velocity channel section is obtained as:

$$
A=\frac{Q_{2}}{V}
$$

The top width of the channel is obtained by integration as follows:

$$
A=\int 2 x d y=\int 2 x \frac{d y}{d x} d x
$$

From equation (8) we have:

$$
\begin{aligned}
\frac{d y}{d x} & =\frac{R}{\sqrt{x^{2}-R^{2}}} \\
\therefore \quad A & =\int 2 x \frac{R}{\sqrt{x^{2}-R^{2}}} d x
\end{aligned}
$$

vi) Let $T_{w}$ be half of the top width at the free surface of the channel. 


$$
\begin{aligned}
& \therefore \quad A=\quad \int_{R}^{T_{w}} 2 R \frac{x d x}{\sqrt{x^{2}-R^{2}}} \\
& \text { or } \quad A=2 R\left[\sqrt{x^{2}-R^{2}}\right]_{R}^{T_{w}} \\
& \text { or } A=2 R\left[\sqrt{T_{w}^{2}-R}\right] \\
& \text { i.e. } \quad T_{w}=\sqrt{\left(\frac{A}{2 R}\right)^{2}+R^{2}}
\end{aligned}
$$

(vii) The depth $\mathrm{D}$ of the constant velocity channel section is given by equation (11)

$$
\begin{aligned}
& \text { i.e. } D=R \operatorname{Cosh}^{-1}\left(\frac{T_{w}}{R}\right) \\
& \text { or } D=R\left[\ln \left\{\left(\frac{T_{w}}{R}\right)+\sqrt{\left(\frac{T_{w}}{R}\right)^{2}-1}\right\}\right] \text { for } T_{w} \geq \mathrm{R}
\end{aligned}
$$

viii)If $D$ is too deep or too shallow, R can be varied so that the appropriate $T$, and $D$ values are determined.

Rectangular channels designed to handle both storm water and dry weather flows shown in Fig. 5 (a, b, c) can (using the constant-velocity channel approach) be designed to have channel shapes as shown in Fig. 6 (a, b, c). Construction of this channel section will be more difficult than the normal rectangular sections; nevertheless, in this era of technological advancement when precast units are becoming very common, this section can be achieved in practice using precast units.

\section{Illustrative Example}

A concrete lined open channel is to be constructed at a constant bed slope to serve as the outfall drain for a township. The design peak discharge (including dry weather flow) is $2.8 \mathrm{~m}^{3} / \mathrm{sec}$, and the flow in the channel is required to remain constant at $0.6 \mathrm{~m}^{3} / \mathrm{sec}$. Use channel $6(\mathrm{a})$, and take the diameter of the semi-circular channel to be $1.2 \mathrm{~m}$.

\section{Solution}

Using the steps outlined in the design application

Step I Peak discharge $=2.8 \mathrm{~m}^{3} / \mathrm{sec}$

Step II Estimation of dry weather (minimum flow) - $\left(\mathrm{Q}_{\min }\right)$

$$
\begin{gathered}
\mathrm{Q}_{\min }=\mathrm{VA}=0.6 \times \pi \times \frac{(1.2)^{2}}{8} \\
=0.34 \mathrm{~m}^{3} / \mathrm{sec} \\
\text { and } \mathrm{R}=0.06 \mathrm{~m}
\end{gathered}
$$


Step III Discharge through the constant velocity channel section (Q) $\mathrm{Q}=2.8 \mathrm{~m}^{3} / \mathrm{sec}-0.34 \mathrm{~m}^{3} / \mathrm{sec}=2.46 \mathrm{~m}^{3} / \mathrm{sec}$

Step IV Recommended Constant Velocity

$$
\mathrm{V}=0.6 \mathrm{~m} / \mathrm{s}
$$

Step V Wetted area of constant Velocity Channel Section (A)

$$
A=\frac{Q}{0.6}=\frac{2.46}{0.6}=4.1 \mathrm{~m}^{2}
$$

Step VI Calculation of Top width (free surface) of channel $\left(\mathrm{T}_{\mathrm{w}}\right)$

$$
\begin{aligned}
T_{w}=\sqrt{\left(\frac{A}{2 R}\right)^{2}+R^{2}}=T_{w} & =\sqrt{\left(\frac{4.1}{1.2}\right)^{2}+0.6^{2}} \\
& =3.5 \mathrm{~m}
\end{aligned}
$$

Top width of channel $=\quad 7.0 \mathrm{~m}$

Step VII Calculation of depth of the constant Velocity Channel Section (D)

$$
\begin{aligned}
D & =R\left[\ln \left\{\left(\frac{T_{w}}{R}\right)+\sqrt{\left(\frac{T_{w}}{R}\right)^{2}-1}\right\}\right] \quad \text { for } T_{w} \geq \mathrm{R} \\
D \quad & =0.6\left[\ln \left\{\left(\frac{3.5}{0.6}\right)+\sqrt{\left(\frac{3.5}{0.6}\right)^{2}-1}\right\}\right] \quad \text { for } T_{w} \geq \mathrm{R} \\
= & 1.5 \mathrm{~m}
\end{aligned}
$$

Step VIII Since D $=1.5 \mathrm{~m}$ is normal for outfall drains there is no need for any adjustment of $\mathrm{R}$

\section{Further Research}

As shown in Figure 6, the bottom channels designed to handle the dry-weather/low flows have a bottom surface, hence the velocity distribution in the vertical direction will be controlled by equation (2). The larger top channel will behave as a constant velocity channel - equation (11). In practice however, there will be a transition zone from the point where the logarithmic velocity distribution gives way to the constant velocity distribution. The velocity distribution in the transition zone is best determined by laboratory tests.
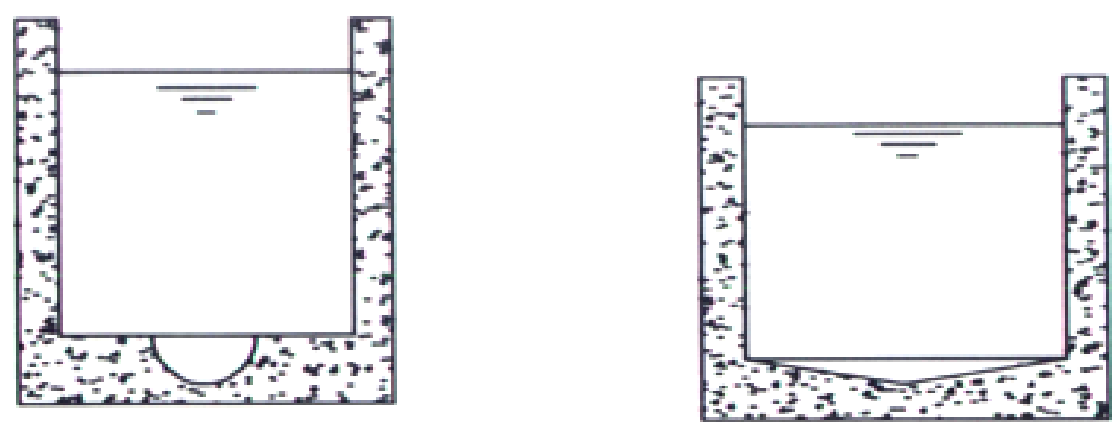

(b) Triangular bottom 


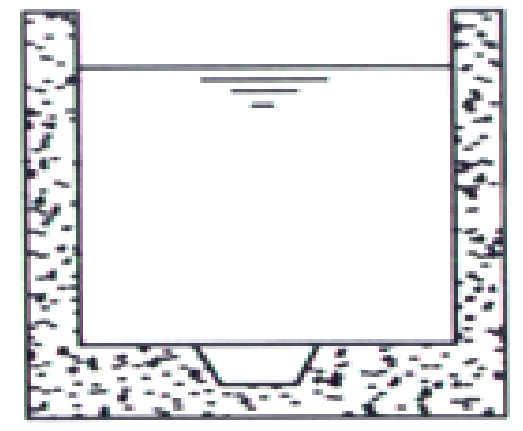

(c) Trapezoidal bottom

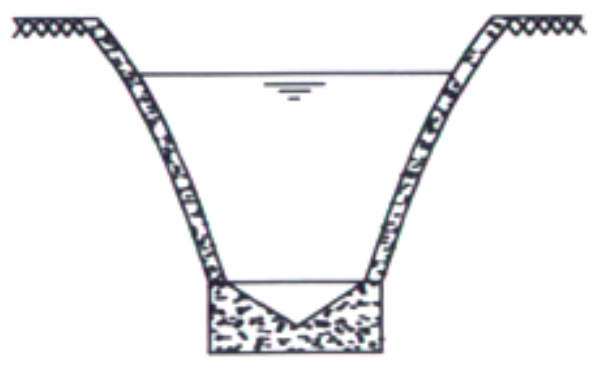

(b) Triangular bottom

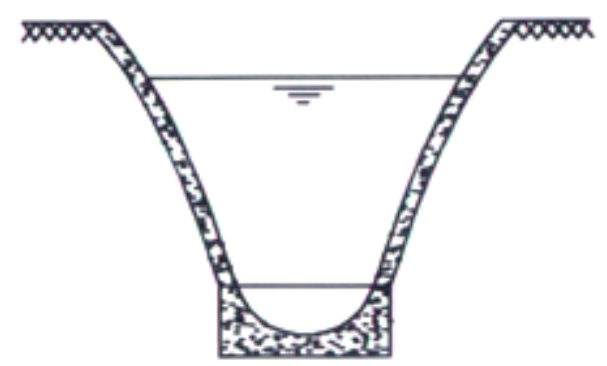

Figure 5:(a) $\mathrm{U}$-shape bottom

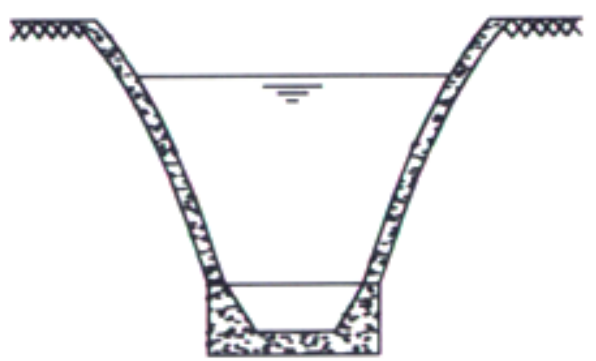

(c) Trapezoidal bottom

\section{CONCLUSION}

Shapes of objects (through which or around which fluid flow occurs) have contributed greatly to the application of fluid mechanics in many fields of engineering practice. A typical example is the shape of the hydrofoil which produces a great reduction in pressure drag on it when moving through a fluid. This has been the philosophy behind the search for the constant velocity channel presented in this study as a means of minimizing sediment deposition in urban drainage channels in Ghana.

Probably because of the construction difficulty of the shape, its application has been limited to a few sewage channels in which the solid particles are required to be kept in a constant motion to avoid clogging. In this era of precasting technology and complex formwork systems, it is possible to construct and use the constant velocity channel in urban stormwater drainage systems in areas where the flows carry large quantities of sediment through relatively flat areas and sediment deposition often takes place. Adequate lateral space is however required to accommodate its relatively wide top section. 
A thorough understanding of this channel section will be obtained when the velocity distribution within the transition zone between the dry weather flow section and the constant velocity channel section is studied.

\section{ACKNOWLEDGEMENTS}

The contribution of Ms. Mavis Adade of The Consortium (a Civil Engineering, Architecture, and Planning Firm in Accra), and Ms. Diana Deegbe, a final year civil engineering student (June 2002) to this study is gratefully acknowledged.

\section{REFERENCES}

Ackers, J.C., Butler, D. and May, R.W.P. (1996). Design of Sewers to Control Sediment Problems, Report R141, CIRIA, London.

Arthur, S., Ashley, R., Tait, S. and Nalluri, C. (1999). Sediment transport in sewers - a step towards the design of sewers to control sediment problems. Proceedings of Institution of Civil Engineers, Water, Maritime and Energy, 136, March, 9-19.

BS EN 752 - 4:(1998). Drain and Sewer System Outside Buildings. Part 4: Hydraulic Design and Environmental Considerations.

Butler, D. and Davies, J.W. (2000). Urban Drainage, E \& FN Spon, London, Chapter 15.

Butler, D., May, R.W.P. and Ackers, J.C. (1996a). Sediment transport in sewers - Part 1: Background. Proceedings of Institution of Civil Engineers, Water, Maritime and Energy, 118, June, 103 - 112.

Butler, D., May, R.W.P. and Ackers, J.C. (1996b). Sediment Transport in Sewers - Part 2: Design. Proceedings of Institution of Civil Engineers, Water, Maritime and Energy, 118, June, 113-120.

Kennedy, J.F. and Brooks, N.H. (1963). Laboratory Study of an alluvial stream at constant discharge. Proceedings of Federal Interagency Sediment Conference, U.S. Department of Agriculture, ARS 970, pp 320-329.

Lane, E.W. (1937). Stable Channels in erodible materials. Transactions of American Society of Civil Engineers, Vol. 102, pp 123-194

Leopold, L.B. and Maddock, T. (1955). The hydraulic geometry of stream channels and some physiographic implications. U.S. Geological Survey Professional Paper 252.

Nyameche, I.K. (1996). Searching for the "best channel section" for stormwater drainage in Ghana. Proceedings of the $27^{\text {th }}$ Annual General Meeting and Conference, Ghana Institution of Engineers, Accra, March, 45-51.

Okine, C.B. (2002). AMA needs $\not 3.5$ bn to desilt drains. Daily Graphic, Monday, June 17, No. 148551, pp 28.

Rouse, H. (1950). Engineering Hydraulics - Proceedings of the Fourth Hydraulics Conference - John Wily \& Sons, Inc., 217-218. 